\title{
ASPECTOS MACROECONOMICOS \\ DEL PENSAMIENTO DE ALFRED MARSHALL: TEORIA MONETARIA *
}

\author{
FERNANDO MENDEZ IBISATE \\ Univeraidad Complutence de Madrid
}

\section{RESUMEN}

Alfred Marahall ha pasado a la historia de la teoria económica como macatro en el campo microeconómico. Sus aportaciones a las teorias del valor, la demanda, la ofertin, La discribución o la organización induatrial han eclipado oures, no menos rignificatives, - las teorias del dinero, los ciclos, o del comercio internacional. El presente trabajo quiere recoger algunas de esas contribuciones, si bien se centra en su teoría monetaria que, formulada por encima de intereses pricticos o de politica, ha recultado ser un es. labón esencial en la trasmisión de la teoria monetaria que ha llegado hasta nuestros dias.

\begin{abstract}
Alfred Marahall has long been recognized as an important figure in the development of rigorous microeconomic theory. His contributions to the theories of value, demand, aupply, distribution and induarrial organization have often overahadowed his other, no less siznificant, contributions to theories of money, busineses cycles, and international trade. This paper concentrates on Marahalls influence on monetary theory, which carries forward to this day, and angues that his theory of money did not arise from his role as an adviser to the British Parliament.
\end{abstract}

* Agradezco al profesor Carlos Rodriguez Braun sus comentarios a una versión preliminar de este articulo, así como las sugerencias y observaciones de un referee anónimo de esta revista. Por descontado, los errores son únicamente imputables al autor. 
Quien sölo conozca los Principios no conoce a Marshall..

J. A. SCHUMPETER

\section{INTRODUCCION}

Este articulo pretende reivindicar las aportaciones que hizo Alfred Marshall a la macroeconomía, y en particular a la teoria del dinero. Su peculiar conocimiento de las cuestiones y el enfoque microeconómicos le permitieron aplicar las herramientas que había desarrollado para la teoría del valor a los problemas teóricos del dinero, y extraer, así, una teoría monetaria a la vez continuadora de la ortodoxia clásica y pionera de ulteriores desarrollos, como los de J. M. Keynes y algunos monetaristas, constituyendo un eslabón esencial en la evolución de dicha teoría 1.

En otra parte he afirmado que las aportaciones de Marshall al campo de la teoría económica, principalmente las relativas al desarrollo de las teorias del valor y de la distribución, han sido ampliamente reconocidas por el conjunto de la profesión y nadie ha negado su puesto entre los maestros de nuestra ciencia. Pero la valoración de Marshall como economista monetario no ha sido la misma y se ha cometido cierta injusticia con él 2. Pese al interés y aportaciones de sus escritos monetarios recogidos principalmente, aunque de forma tardia, en su obra Money, Credit and Commerce, sus Principles of Economics han os. curecido otras contribuciones de Marshall 3.

1 Vid. Méndez Ibisate (1988a), caps. I, III y Conclusiones Generales. No sólo es Alfred Marshall heredero de toda una tradición de pensamiento monetario que se remonta hasta Henry Thornton y llega a John Stuart Mill, pasando por su lectura de Walter Bagehot y la aceptación de sus principios de organización del sistema monetario, sino que deja su huella y su influencia en autores que posteriormente desarrollaron la teoria monetaria en nuestro siglo (Fisher, Wicksell, J. M. Keynes, y M. Friedman).

En mi teais doctoral ya destaqué que la teoria monetaria de Marshall brilla con luz propia (independientemente de les cuestiones de política monetaria en las que Marshall participö), ha supuesto un eslabón de continuidad en una corriente del pensamiento monetario (la de la Banking School) y ha influido muy de cerca el posterior desarrollo experimentado por las ideas monetarias en el presente siglo. De ahi su importancia [vid. Méndez Ibisate (1988a), p. 255, y caps. I y III].

2 Méndez Ibisate (1988a). Véase al respecto, principalmente, el cap. III.

3 Laidler (1990a) afirma:

«El "enfoque de demanda de saldos reales de Cambridge" es de sobra conocido en teoria monetaris, pero normalmente se le denomina como el "enfoque de Cambridge" y no como el "enfoque de Marshall"; $y$ los estudiantes que sienten ilusion por aprender más de dicho enfoque se les remite a los trabajos de Pigou (1917), [The Value of Money", Quarterly Joumal of Ecomomics, 32:38-65] o de Keynes (1923), [A Tract on Mometary Reform, Londres, Macmillan] en vez de a los eacritos de Marshalls [Leidler (1990a), p. 44]. 


\title{
Hasta 1987 apenas unos cuantos autores, como Krishnaswamy y Eshag,
} dedicaron un esfuerzo a estudiar las contribuciones de Alfred Marshall al campo monetario 4 . Sin embargo, este panorama ha cambiado, y desde esa fecha se han publicado varias obras en las que se dedica un espacio importante a la teoria monetaria de Alfred Marshall y a su papel como fundador de la tradición de pensamiento formada en Cambridge. Estas obras son las de Pascal Bridel, Robert J. Bigg, David Laidler y David Laidler '.

Incluso circulaba entre la profesión la opinión, inspirada en una cita de J. R. Hicks, de que la teoria monetaria de Marshall tenía poco interés porque los problemas monetarios de su época no fueron importantes ${ }^{6}$. Sin embargo, como ha demostrado Laidler, «la teoria monetaria de Marshall tiene una importancia mucho más general que los problemas [de politica] a los cuales la aplicó ?. Por tanto, y pese a sus innegables contribuciones a la política moneta-

4 Méndez Ibisate (1988a), p. 284 y nota 57 (pp. 349-350).

S Los capítulos dedicados a la teoría monetaria de Alfred Marshall de los dos primeros libros aqui citados no pasan de ser elementales ya que ambos autores pretenden estudiar a toda la escuela de Cambridge (Marshall, Pigou, Keynes, Hewtrey, Lavington y -el más apartado- Robertson...) y establecer las oportunas conexiones de pensamiento macroeconómico (dinero, ciclos, análisis del ahorro-inversión, influencias del tipo de interés...) entre todos ellos.

Quisier incluir entre las aportaciones realizadas al estudio de la teoria monetaria de Marshall, a partir de 1987, mi tesis doctoral [Méndez Ibisate (1988a)]. Las lineas de investigación allí desarrolladas se asemejan más a los estudios publicados por Laidler (1990a) y Laidler (1991), si bien he completado y ampliado mis ideas gracias a los análisis y conclusiones expuestos por Laidler.

Laidler (1991) extiende su estudio a lo que denomina la teoria cuantitativa neoclósica (Marshall y la Escuela de Cambridge, Fisher, Wicksell y Edgeworth), en una comparación con la teoria cuantitativa clásica, anterior a estos autores (J. S. Mill, Jevons y Bagehot).

- La cita de Hicks es la siguiente:

\begin{abstract}
La mayor parte de los mejores trabajos de teoria monetaria han sido directamente provocados por epieodios particulares, por experiencias de la época. Es posible que una de las razones por las que la teoria monetaria se fue osificando un tanto en el periodo neoclésico sea que en esta época no parece que hubiera ningun reto similar (a los de Ricardo o Keynes en sus periodos respectivos). Por lo menos en los años setenta y ochenta, cuando Marshall (el mis grande de los neoclíaicos) hubiera podido responder al reto, resultó que el reto no estaba alli; jo podia sacarse demasiado partido del bi. metalismo! Uno no puede contestar brillantemente las preguntss poco inteligentes, y las preguntus que los hechos monetarios de la época plantearon a Marshall no eran demasiado dificiless (Hiclas (1975), pp. 185-186. Citado en Méndez Ibisate (1988a), p. 377; vid pp. 32 y 288].
\end{abstract}

7 Laidler (1990a), p. 46. Laidler (1991) sostiene como una idea principal lo contrario que Hicks: que los hechos y los problemas de política monetaria apenas afectaron el desarrollo y la evolución de las ideas y teorias monetarias formuladas por Marshall y otros neoclasicos; más bien al contrario:

Le evolución de la economia monetaria debió mis a su propia dinámica interna que a los acontecimientos externos, y la lógica de la teoría cuantitativa ideurrollada en eate tiempo por autores como Marshall, Fisher o Wickell) subvirtió la autoridad intelectual del Patrón Oros [Laidler (1991), p. 3].

Que la teoria monetaria de Marshall se desarrolló con independencia de sus propuestas politicas, que éstas se derivan de aquélla y no al revés (como casi siempre se ha interpretado), y que 
ria (que serán objeto de otro articulo), la teoria del dinero desarrollada por Marshall tiene validez en si misma, como el producto de un trabajo puramente académico, que sin embargo aplicó - como era su costumbre - a problemas prácticos, y lo hizo de forma notable.

Pese a la poca atención prestada a su pensamiento monetario, la importancia e influencia de Marshall en esta materia habia sido recogida en el articulo biogräfico de J. M. Keynes ${ }^{8}$ y, posteriormente, en la obra de Eprime Eshag 9. Eshag muestra que Marshall es heredero de una larga lista de autores que fueron considerados creadores y maestros del pensamiento monetario, y que, a su vez, Marshall afue leído y escudriñado por otros autores que contribuyeron al campo de la economia monetaria lo bastante pronto como para ser importantew. De modo que kel caso de Marshall no es el de un economista monetario cuyas contribuciones originales permanecieron ocultas hasta el momento en que su importancia hubiese desaparecidow ${ }^{10}$. Por el contrario, Marshall fue reconocido por otros autores fuera de su propio circulo tales como Fisher (que menciona la distinción entre las tasas reales y nominales de interés), Edgeworth (que estaba al tanto de su propuesta del «Symmetallismo) o Wicksell (quien estaba familiarizado con sus testimonios ante la Gold and Silver Commission) "

El presente trabajo quiere exponer las nuevas ideas aportadas por Marshall a la economia monetaria y su trascendencia teórica. En la sección 2 se recogen algunas razones por las que esta aportación marshalliana a la teoría monetaria pudo haber pasado inadvertida para los historiadores de la teoria económica. Entre otras, se destacan razones de tipo histórico. La sección 3 presenta las ideas heredadas por Alfred Marshall en su pensamiento moneta-

la teoria monetaria de Marshall es superior a la de sus predecesores y muchos de sus contempo. ráneos, son ideas que defendi en Méndez lbisate (1988a), unos años antes de las publicaciones de Laidler.

8 Keynes (1925). Como articulo biográfico, sin embarggo, el documento de J. M. Keynes contiene diversas inexactitudes y datos que recientemente se han revelado como incorrectos. Vid. Whitaker (1972), Coase (1984) y Coase (1990).

- Eshag (1965). El libro de Eprime Eshag fue pionero en el análisis de Marahall como macroeconomista y, aunque algunas de sus consideraciones puedan estar superadas, quienes hemos investigado la teoria monetaria de Marshall o de la Escuela de Cambridge tenemos esta obra como punto de referencia obligado.

10 Leidler (1990a), P. 45 (ambas cites).

Entre sus predecesores podriamos mencionar a Hume, Smith, Ricardo, Thornton y J. S. Mill. Entre sus contemporáneos, a Jevons, Goschen, Giffen y Bagehot. Y entre sus discipulos, a los miembros de la escuela de Cambridge (Pigou, Keynes, Hawtrey, Lavington y Robertson). Vid. Eshag (1965), pp. 91 -96 y 100-110, por ejemplo. Véase tumbién Méndez Ibisate (1988a), nota 190, p. 905. Puede completarse la visión de Eshag en Méndez Ibisate (1988a), p. 569, nota 23.

Para ouros eatudios, véanse las obras de Bridel (1987), Bipg (1990) y Laidler (1991).

1 Vid Laidler (1990a), p. 45. Y, més ampliado, en Laidler (1991). 
rio, reforzando la tesis de una continuación en la línea de pensamiento teórico. La sección 4 recoge las innovaciones de Marshall respecto al valor del dinero, la demanda y la oferta de dinero (siguiendo un esquema de razonamiento típicamente marshalliano), asi como otras aportaciones. Finalmente, la sección 5 presenta algunas conclusiones.

\section{OBSTACULOS QUE DIFICULTAN EL RECONOCIMIENTO DE LAS CONTRIBUCIONES DE MARSHALL} A IA ECONOMIA MONETARIA

El pensamiento monetario de Alfred Marshall no está recogido en un único volumen sistemático ${ }^{12}$. Cuando Marshall publicó su Money, Credit and Commerce, un año antes de su muerte, las ideas alli presentadas no eran sino el fruto de sus investigaciones durante las décadas de 1870 y 1880 (uno de los primeros campos de investigación de Marshall, como afirman J. M. Keynes y J. K. Whitaker).

Pero, como señala Laidler, no es éste el único impedimento ante el que se enfrenta el investigador moderno que desea valorar la aportación marshalliana a la teoria monetaria. Los problemas que rodeaban la época de Marshall fueron muy distintos de los que nos rodean hoy en día. No fueron problemas de inflación y fluctuaciones reales, con un mundo en el que dominaban los tipos de cambio flexibles, como en época de Thornton (1802), Ricardo (hasta 1821) o el Keynes del Tract sino que se trató de una época de deflación, en la que la implantación del patrón oro se estaba generalizando y donde las fluctuaciones ciclicas resultaban muy apacibles ${ }^{13}$.

Históricamente, durante la segunda mitad del siglo xix la teoría económica estuvo centrada en el examen de las fluctuaciones de los precios a largo plazo y de los movimientos ciclicos en el comercio y en el empleo. La explotación de minas de oro en California y Australia alrededor de 1850 se vio seguida por un periodo de más de veinte años en el que la tendencia general de los precios fue fuertemente ascendente, aunque rota, a veces, por las fluctuaciones

12 Además de en Marshall (1923), se encuentran desperdigadas en alguin articulo como Mars. hall (1887), en diversos testimonios y evidencies presentados por Alfred Marahall ante diferentes comisiones parlamentarias (Commiscion on the Depression of Trade and Industry -1886-; Tbe Gold and Silver Commission -1887/8-; y The Indian Cumency Committe -1899-), recopilados en Marshall (1926), y en Marshall (1871), publicado en Whitaker (1975). Ello sin mencionar algunos paeajes de A. Marshall and M. P. Mershall (1879), y alguna mención desperdigada en Marshall (1890).

13 Laidler (1990a), pp. 45-46. 
cíclicas. A comienzos de la década de 1870 , sin embargo, la producción de oro comenzó a disminuir, mientras que la demanda del mismo iba en aumento a medida que crecía el número de paises que adoptaban el patrón oro. Los precios de las mercancias comenzaron a bajar y la tendencia descendente continuó hasta 1896, cuando el descubrimiento de oro en Suráfrica y en el Yukon se vio acompañado por un período caracterizado nuevamente por una tendencia ascendente, que continuó hasta la Primera Guerra Mundial. El periodo de la tendencia deflacionista de los precios produjo tantas quejas por parte de los comerciantes que se encontraban en apuros, que dio origen a la demanda de un patrón bimetálico, lo que desembocó en una aguda polémica ${ }^{14}$.

Otros factores que han influido en el escaso reconocimiento y difusión de la teoría monetaria de Alfred Marshall son el retraso con que publicó sus ideas, en este como en otros campos ${ }^{15}$, y que su teoria y política del dinero quedó fuera de su obra principal, los Principios de Economia, que eclipsó otras contribuciones de Marshall.

Las causas del retraso en sus publicaciones residen en su doble faceta de práctico y teórico, el Marshall positivo y el Marshall normativo, el cientifico y el moralista. Esa lucha le llevó a cuidar mucho las formas con que presentaba sus escritos, ya que temía enormemente cometer errores, y queria ser entendido por el público en general y no por los especialistas. Además está su falta de

14 Vid Méndez Ibisate (1988a), pp. 214-215. El descenso de precios a comienzos de la década de 1870, que persistió hasta mediados de la década de 1890 , fue ocasionado tanto por la continua extensión del monometalismo de oro en todo el mundo como por la desaparición gradual de los efectos que los descubrimientos de las minas de Australia y California (1849-1851) habian tenido sobre el precio del oro y, por consiguiente, sobre el nivel general de precios. La combina. ción de un aumento en la demanda de oro, junto con una oferta descendente (la producción de oro en las minas descubiertas en torno a 1850 ya había sobrepasado su máximo), provocó un aumento en el precio del oro, es decir, una caída en el nivel de precios medido en oro, en tanto que el nivel de precios medido en plata se elevó, y la rupia de plata india se depreció contra la libra esterlina de oro.

Algunos viejos fantasmas no han desaparecido en economia, y en aquel entonces, como ahora, era muy fícil (aunque no por ello correcto) afirmar que la deflación de precios provocaría un estancamiento en el lado real de la economia y que la revaluación de la moneda causaria una pérdida de competitividad para las industrias domésticas.

Las discusiones sobre el bimetalismo aparecieron, entonces, para diseñar un sistema alternativo al Patrón Oro que dotase a la economia de unos precios mas estables; estabilidad de precios que era requerida como objetivo principal.

Un análisis histórico de los acontecimientos monetarios de la época puede encontrarse en Rist (1966), pp. 246-247, 252-254 y 292-297; y en Laidler (1991), pp. 29.32 y 154170.

13 Ya hemos señalado que aunque su libro Money, Credit and Commence se publicó un año an. tes de su muerte -1923-, recoge ideas y teorias formulades posiblemente entre 1867 y 1877. De modo que muchas idees pioneras que podian haber tenido como punto de referencia las publicaciones de Marshall tuvieron las de otros autores. Véase al respecto Keynes (1925), pp. 18, 28-29 y nota 3 a pie de p. 28 . O véase también Laidler (1991), pp. 53 y ss., y p. 86, nota 8. 
salud, que - aunque parece no exenta de elementos hipocondriacos- le apartaba continuamente de su trabajo y le impedía la concentración 16.

- Por otra parte, Marshall no incluyó ciertos temas, como el dinero, en los Principios porque, según nos cuenta él mismo, los Principios de Economía formaban sólo una parte de un tratado general de obras de economía - un compendio de temas económicos- que, según proyectaba Marshall, constituiría su legado impreso para sus discípulos ${ }^{17}$.

\section{ELEMENTOS CLASICOS EN EL PENSAMIENTO MONETARIO DE MARSHALL}

En líneas muy generales podemos resumir la teoria monetaria que habia llegado hasta Marshall en la década de 1870 en una serie de temas interrelacionados: la teoría de la paridad de compra, el ciclo, la balanza de pagos, la elección de un patrón monetario que cumpliese adecuadamente con sus funciones, y dentro de las restricciones impuestas por el patrón elegido, la adopción de políticas monetarias discrecionales o no ${ }^{18}$.

Cuando se utilizaba un patrón de valor-mercancía (oro o plata) la balanza de pagos se equilibraba siguiendo una versión compleja del «mecanismo de flujo de especie» de Hume-Cantillon, y el nivel general de precios quedaba determinado, a largo plazo, por el coste de producción de la mercancia utilizada como patrón ${ }^{19}$. Esta teoria se complementaba con una teoria del valor de equilibrio a largo plazo de la tasa de interés en términos reales (no dependía de

16 Tenia Marshall una peculiar forma de concentración que le impedia mantener su atención fija durante mucho tiempo en una cosa, pese a que cuando lo lograba su concentración era muy intensa. A eso habria que añadir su desorden y su carencia de sistematización, según Keynes. Vid Méndez Ibisate (1988a), pp. 296-297, 299-302, 315-318, 321-322 y 324-329.

17 Vid. Méndez Ibisate (1988a), pp. 302-334.

18 Vid. Laidler (1990a), p. 46. El análisis expuestọ en Méndez Ibisate (1988a) respecto a este apartado coincide con el de Laidler (1990a), pp. 46-52. Una exposición amplia de estas teorias decimonónicas del dinero en Méndez Ibisate (1988b).

19 No es ésta sino una forma de aplicar la teoria general del valor de los clísicos a un bien peculiar, como el dinero, que era considerado como cualquier otro. A corto plazo, el valor del dinero quedaba establecido por el libre juego del mercado (oferta y demanda del mismo); y a largo plazo, se seguia la teoria del valor o precio natural (su coste de producción). Esta teoria, que integraba la teoria monetaria en la teoría del valor, aunque trasladaba a aquélla los problemas de este doble proceso de formación del valor, estaba inspirada en (o, más bien, era) la teoría de la "cantidad de dinero de los precios. Lejos, pues, de dicotomizar el proceso de formación de precios, la teoría de la acantidad de dinero" de los precios, en sus versiones clásica y neoclásica rigurosas, tomaba en consideración las interconexiones entre el sector real y el monetario de la economia cuando existía un mercado monetario importante. Vid. Becker y Baumol (1952). Citado en Méndez Ibisate (1988a), pp. 365, 599.600. 
factores monetarios), de forma que en la determinación a largo plazo de esta variable intervenian elementos como la productividad real del capital y el ahorro (o la frugalidad). De este modo, en el largo plazo y sólo aquí, la teoria monetaria clásica - recibida por Marshall-establecia la neutralidad del dinero y dicha variable tan sólo determinaba el nivel general de precios.

Las cosas en el corto plazo no eran tan sencillas y el dinero no era neutral. En el corto plazo, la teoría de la «cantidad de dinerow de los precios explicaba el valor del dinero (los precios), a través de la oferta y la demanda, de modo que sobre el nivel de precios influian tanto las variaciones en la cantidad de dinero como las variaciones en la velocidad de circulación (determinadas, a su vez, por el desarrollo de las actividades del sistema bancario). Al igual que el valor del dinero podía desviarse de su valor natural en el corto plazo, la tasa de interés fluctuaba con las perturbaciones monetarias, si bien se entendia que el corto plazo era mucho más corto para los movimientos del tipo de interés (y por tanto los ajustes hacia su valor natural eran más rápidos) que para los del nivel de precios. Una expansión monetaria se asociaba con una caida del tipo de interés del mercado por debajo de su nivel «naturalw, y al revés. Estos movimientos generalmente estaban asociados con las fluctuaciones comerciales y crediticias que se producian tanto en los mercados de bienes como en los mercados financieros.

La política económica discrecional debía ir encaminada no tanto a estabilizar el ciclo como a tratar de evitar que en el punto de inflexión alcista todo se precipitase hacia un pánico financiero y un colapso del sistema bancario.

Cuando el sistema estaba basado en moneda puramente fiduciaria (papel moneda), dicho sistema perdía el freno que el valor natural del oro imponía al exceso de emisión (y por tanto a la devaluación de la moneda); y esto se consideraba como un serio inconveniente por la ortodoxia clásica 20.

Entre las raices más clásicas de la teoria monetaria de Marshall se encuentra su adhesión (ken tanto que actúen los efectos permanentesw) a la dicotomia entre la economía real y monetaria ${ }^{21}$, su teoría de la determinación de la tasa de interés y su análisis de la formación de los tipos de cambio y de la balanza de pagos.

Respecto al tipo de interés, Marshall sostuvo que a largo plazo «la oferte de oro no ejercia influencia permanente alguna sobre la tasa de descuentow; pero

20 Vid. Méndez Ibisate (1988b).

21 Vid Marshall (1926), p. 115, pregunta 9893. Cursivas mies. Véase Méndez Ibisate (1988a), pp. 333.334. 
a corto plazo los factores monetarios podian afectar la tasa de interés 22 (y más en una economia abierta, con unos mercados financieros desarrollados y muy interconectados, como constata en alguna parte) ${ }^{23}$. Considera, pues, la tasa de interés como una parte fundamental de los mecanismos de transmisión, a través de los cuales una afluencia de oro elevaría finalmente el nivel de precios (dejando el interés a su nivel «natural»). En este proceso (que se enmarca dentro de un proceso ciclico), las expectativas desempeñaban un papel importante ${ }^{24}$.

Su análisis sobre la formación de los tipos de cambio es más notable por su concisión y claridad que por su originalidad. Pero Marshall jamás reclamó originalidad alguna ${ }^{25}$. Sus ideas se recogen en algunos de los testimonios publicados en sus Official Papers, y alli expone Marshall de forma simple la teoria de la paridad del poder de compra como determinante de la formación de los tipos de cambio. Asi, los desequilibrios originados en la balanza comercial (incluso la balanza básica) generan tensiones en el mercado de intercambio de letras comerciales (otorgando premios o descuentos, según que el país resulte acreedor o deudor), que, finalmente, provocan flujos de oro (o plata) de un

22 Marshall (1926), p. 41. Un análisis desarrollado de eata influencia se expone en Méndez Ibisate (1988a), pp. 786-790.

${ }^{23}$ Realizo un estudio del papel de la tasa de descuento en la economia abierta, asi como de las manifestaciones de Marshall acerca del desarnollo de los mercados financieros, en Méndez Ibisate (1988a), pp. 667-671.

24 Véase el papel de las expectativas en este punto en Méndez Ibisate (1988a), pp. 790-793 y ss.

Las expectativas en Marshall estin muy influidas por los procesos especulativos del mercado financiero. Es en estos procesos donde cobran o tienen mayor importancia. A diferencia de J. $\mathbf{M}$. Keynes (al menos el Keynes de la Teoría Generah), Marshall construye unas expectativas con un componente lógico en su formación. No se trata de un proceso de formación de expectativas racionales, sino de expectativas adaptativas, en las que el valor más próximo o cercano en el tiempo de las variables relevantes posee una ponderación mucho mayor por parte del público. Esto, desde luego, no es el proceso de formación de expectativas que aparece en la Teoría General de J. M. Keynes, que es más bien irracional o ilógico.

Sin embargo, Marshall admite la existencia de agentes especulativos (mal vistos) que entran en el mercado financiero - unos con pleno conocimiento del mismo, y otros arrestrados por la vorágine del momento-, y que más tarde son víctimas de sus especulaciones (Vid. Méndez Ibisate (1988a), pp. 777 (cita), 778 (cita 108), 779.782 y 796-797). Y dicha creencia por parte de Marshall puede suponer un primer paso hacia la concepción que tenia Keynes de los mercados financieros y de valores, a los que compara con eel juego del Snap, de la Solterona o de las Sillas Musicales, un pasatiempo en el que gana quien dice Snap ni demasiado pronto ni demasiado tarde, quien pasa la "Solterona" (el anillo) a su compañero antes de que termine el juego, o el que consigue una silla en el momento que cese la músicaw. [Vid. Keynes (1936), pp. 155-156 y 150. 151.]

25 Vid Laidler (1990a), p. S0. Expongo el papel que atribuyó Marshall al dinero en una economía abierta, y su anailisis de la formación de los tipos de cambio y del mercado de cambios, en Méndez Ibisate (1988a), cap. V. 
pais a otro, o bien movimientos en los tipos de cambio, que permiten restaurar el equilibrio.

Marshall discute los cambios en la productividad, pero en el contexto en que una depreciación de la moneda interna causada por factores monetarios podría engañar a los exportadores quienes, habiendo obtenido al tiempo alguna ventaja en sus costes, creerian que su mayor éxito en los mercados exteriores se debería a dicha depreciación [Cf. Marshall (1926), pp. 192-193]. Marshall no dis. cutió la posible influencia independiente de la productividad sobre las variacio. nes del tipo de cambio real (y, por consiguiente, ceteris paribus, nominal) ${ }^{26}$.

\section{NUEVAS APORTACIONES DE ALFRED MARSHALL A LA TEORIA MONETARIA}

\section{El valor del dinero}

Marshall superó la inconsistencia de los clásicos en su intento de integrar la teoria del valor en la teoria monetaria. Recordemos que la teoria del valor clásica no era completa, y al aplicarla a un dinero-mercancía (oro o plata) se reproducian los problemas que tenía para cualquier otra mercancía: no era fácil integrar las interpretaciones de la teoría cuantitativa (a corto) y la teoria coste de producción (a largo). Y este enfoque no resultaba del todo satisfactorio porque la extracción del oro era una actividad minera y - por tanto- sujeta a rendimientos decrecientes. Dados los rendimientos decrecientes, el coste marginal de producción (del oro) no quedaba determinado hasta que no se conociese el nivel de producción, por lo que el coste de producción podria no ser el que en última instancia regulase la capacidad de compra del dinero. Sin embargo, como ha señalado Laidler, la teoría cuantitativa establecida por los neoclásicos «degradó el coste de producción de los metales de ser el principal, y en algunos casos único, determinante del valor natural del dinero, a tener una influencia secundaria y remota en su cantidad ${ }^{27}$.

Además, la teoría del nivel general de precios a corto plazo de los clásicos contenía un concepto - el de velocidad de circulación de transacciones- que resultaba en exceso complejo y poco adecuado cuando se aplicaba a una economía en la que la mayor parte del comercio se desarrollaba sobre la base del crédito y que, por tanto, precisaba de un número grande de transacciones in-

26 Laidler (1990a), pp. 51.52.

27 Laidler (1991), p. 4. 
termedias antes de que los bienes en manos de los productores llegasen a las manos de sus consumidores finales.

Marshall encara estos problemas sobre el valor el dinero en sus primeros escritos (en torno a 1871) ${ }^{28}$, y alli expone el llamado enfoque de Cambridge «de los saldos reales» (que debería denominarse el enfoque de Marshall «de los saldos realesw):

Tal vez deberiamos observar... cuál es la naturaleza de la ventaja que cada individuo obtiene por mantener en mano una gran cantidad de dinero. Por este medio el individuo retiene en sus manos lo que podria llamarse una gran disponibilidad efectiva sobre los bienes en general... Pero de esa porción de su riqueza que cada persona mantiene en forma de dinero, es incapaz de derivar cualquier otra ventaja... Así, cuanto mayor es la parte de su riqueza que un hombre mantiene en forma de demanda disponible sobre las mercancias en general, menor es la parte que puede ser empleada bien para abastecer sus necesidades o para incrementar su riqueza. Este, pues, es el equilibrio de ventajas que cada individuo debe ajustar por sí solo... Asi, debe establecer cuál es la cantidad exacta que por promedio responderá a su propósito de mantenerse en esta forma líqui$\mathrm{da} 29$.

Representado mediante ecuaciones -y simplificado-, el enfoque de Marshall queda como un sistema compuesto por:

Una ecuación de oferta:

$$
M^{s}=\bar{M}
$$

Una ecuación de demanda:

$$
M^{d}=k \cdot P \cdot y
$$

La ecuación de equilibrio del mercado:

Por lo que en equilibrio:

$$
M^{s}=M^{d}
$$

$$
\bar{M}=k \cdot P \cdot y
$$

${ }^{28}$ Se trate de Marshall (1871). En mi tesis doctoral se incluye como Apéndice E una traducción completa - con algunos comentarios- de este texto, que se publicará en la revista Libertas. Aunque este texto no se publicó hasta 1975, no ere desconocido. Keynes (1925), pp. 29-30, hace varias referencias y citas del texto, y señala que «Cuando asisti a las lecciones (de Marshall) en 1906 solia ilustrar esta teoria con algunos gráficos elegantesw. [Keynes (1925), p. 29, nota 1.] Vid. también Laidler (1991), pp. 53 y ss.

2 Marshall (1871), pp. 166-167. Justo a continuación, establece Marshall las mismas condiciones para ala cantidad total retenida de esta forma por lo comunidad (cursivas mias).

Véanse ideas similares en Marshall (1926), pp. 267-268, y en Marshall (1923), pp. 38-39 y 45. 
Donde $M^{s}$ es la oferta monetaria nominal $M^{d}$ la demanda de dinero, $P$ el nivel general de precios, el ingreso real es $y, y, k$ la proporción del ingreso nominal, que el público mantiene en forma de saldos monetarios para disponer de una capacidad de demanda inmediata sobre los bienes.

Gráficamente, algunos han representado la curva de demanda como una hipérbola equilátera, lo que es un error por doble motivo: porque para Marshall las variables que intervienen en la demanda, $k$ e $y$, no son constantes, lo que rompe el supuesto (implícito en la demanda con forma de hipérbola equilátera) de que los individuos desean conservar la misma cantidad de saldos reales cuando varian los precios (el valor de su dinero), aunque su situación haya cambiado. En una curva de demanda de saldos de efectivo con elasticidad unitaria (con forma de hipérbola rectangular) el individuo reduce (aumenta) sus saldos nominales cuando los precios bajan (suben), dado el nivel de ingreso real, y lo hace exactamente en la misma proporción en que variaron los precios. Pero desde el momento en que la $k$ de Marshall viene influida, como señalaré más adelante, por variables tales como el tipo de interés y las expectativas, y que - como señala Patinkin- ${ }^{30}$ el volumen proyectado de transacciones queda alterado por el efecto de liquidez real que se origina cuando sólo varía el nivel general de precios (esto implica que el individuo toma en cuenta los efectos-renta provocados en la demanda de dinero cuando varian los precios), entonces la acomodación de la demanda de dinero es proporcional a los precios, pero no exactamente proporcional.

En realidad, esa curva de demanda de saldos reales de dinero en forma de hipérbola equilátera representa una curva de equilibrios del mercado ${ }^{31}$. Como afirma Laidler, «se trata de una curva compensada por las variaciones en la riqueza real que han sido inducidas por los cambios en el nivel general de precios» 32 . En este sentido, la demanda de saldos reales líquidos en forma de hi-

30 Vid. Patinkin (1963), pp. 104-114 y 460-464.

31 Patinkin (1963). Esta idea se reproduce en Blaug (1985), cap. 5.

32 Laidler (1990a), p. 53, nota 10.

Acerca de este tema, véase Méndez Ibisate (1988a), el Apéndice F titulado aLa curva de demanda individual de dinero con elasticidad unitarias.

Otros testimonios de Marshall que contradicen el valor de esa elasticidad, en Méndez Ibisate (1988a), pp. 447-448. Alli se recoge el siguiente texto de Marshall:

Aunque el poder adquisitivo de una unidad monetaria varia inversamente al número de unidades, manteniéndose los demis factores constantes, una emisión creciente de moneda papel inconvertible puede rebajar ain mis su crédito y, por tanto, disminuir la cantidad de poder adquisitivo disponible que el público denee conservar. Es decir, puede rebajar el velor de cada unidad en proporción mayor al incremento de su nümero.. un aumento en su cantidad que parezca probable que se repita, disminuiré el valor de cada unidad más que proponcionalmente al incremento [Marshall (1923), Pp. 47-48. Cursivas en el original].

De modo que la elasticidad precio de la demanda es mayor que uno en términos absolutos, si no interpreto mal.

Ver también este tratamiento de Patinkin en Blaug (1985), pp. 206-210. 
pérbola equilátera sería una curva de demanda sin efectos renta, tal y como interpretó Milton Friedman la curva de demanda individual marshalliana para los bienes en general ${ }^{33}$.

No pretende Marshall elaborar tan sólo una teoría de la demanda de dinero, sino formular una teoria del valor del dinero ${ }^{34}$. Su forma de enfrentarse a este problema (con las herramientas microeconómicas que él desarrolló) le permite construir dicha teoría sobre la base de la oferta y la demanda, tanto a corto como a largo plazo. Y es en el largo plazo donde la demanda de dinero sí se representaria con elasticidad unitaria 35 .

Su exposición puramente teórica es una muestra de que a Marshall le interesaba más enfrentarse a los problemas existentes en el esquema teórico interno del análisis monetario que había heredado de los clásicos (sobre todo de J. S. Mill) que responder a los problemas de política monetaria contemporánea.

El otro inconveniente de la teoria clásica ${ }^{36}$ lo resolvió Marshall desechando el concepto de «velocidad de circulación" de las transacciones:

la svelocidad de circulación» no es el concepto más conveniente en el que basar nuestras investigaciones..

El hecho de que, en general, los bienes pasan a través de un gran pero variado número de manos en su camino desde el productor al consumidor, no afecta la validez de nuestra investigación original. Sin embargo, cuando intentamos establecer una conexión entre ala velocidad de circulación y el valor del dinero, se introducen graves complicaciones. Mr. Mill es consciente del mal, pero no señala el remedio ${ }^{37}$.

Esta forma de actuar es congruente con su objetivo: proporcionar una teoría del valor del dinero y no una teoría de la demanda de dinero ${ }^{38}$.

\section{La demanda de dinero}

No me voy a detener en un anälisis pormenorizado de la demanda de dinero por parte Marshall. A su ya citada exposición del enfoque de los saldos

3) Vid. Friedman (1949).

34 Vid. Laidler (1990a), p. 53.

3s La curva de demanda de dinero en forma de hipérbola rectangular representaria, asi, diferentes situaciones de equilibrio a largo plazo, en los que los individuos habrian descontado los efectos renta. Sobre el valor del dinero a largo plazo véase Méndez Ibisate (1988a), p. 391, texto con numeración 58, a final de la pagina, donde Marshall renuncie al enfoque del coste de producción como determinante del valor del dinero a largo plazo. En los siguientes apartados am. plio el anilisis sobre la demanda y ho oferta de dinero, que hasta el momento ha sido considerada como una variable exógena, pero que no siempre fue asi en el anäliais de Marshall.

36 La complejidad e inadecuación de la variable svelocidad de circulación de las transaccioness a las situaciones en que los intercambios se hallan basados casi plenamente en el crédito, y existen multiplicidad de transacciones intermedias.

37 Marshall (1871), pp. 166 y 169.

4. Vid Marshall (1871), pp. 165-166. Cuando uno empieza a leer el texto del «Essay on Mo- 
reales voy a añadir dos afirmaciones que trataré de demostrar: a) Marshall no consideró que las variables que formaban parte de su enfoque de la demanda fuesen constantes o estuviesen dadas por factores exógenos; y b) el peculiar enfoque dado por Marshall al estudio de la demanda le permitió establecer en gran parte los motivos de demanda (motivo de transacciones, precaución y especulación) de dinero, enumerados y analizados explícitamente por Keynes en su Teoria General 39.

Según Marshall, la relación que establece la teoria de la «cantidad de dinero» de los precios «entre cantidad de circulante y nivel general de precios puede modificarse permanentemente por diversas causasw:

Primero, por cambios en la población y riqueza que varien el ingreso total; segundo, por el desarrollo de las entidades de crédito, que suplen el dinero con otros medios de pago; tercero, por los cambios en los procedimientos de transporte, de producción y de los negocios en general [mejoras en la productividad inducidas por mejoras tecnolögicas y mejoras de organización], que afectan el número de manos por las que van pasando las mercancias en su proceso de fa-

neym, lo primero que se encuentra es una formulación básica y resumida de la formación del valor en las mercancias. Tras dejar claro Marshall que ese es el problema para el caso del dinero, se adentra a estudiar los motivos de demanda de saidos reales de dinero.

39 Remito al lector que desee comprobar este punto a Méndez Ibisate (1988a) donde, tras una exposición simplificada -y siguiendo los manuales al uso- del tratamiento teórico de cada uno de los tres motivos de demanda de dinero, intento aportar textos originales de Marshall que corroboren mi afirmación.

Los textos originales para el motivo de transacciones se reproducen en ibid, pp. 515-519; para el motivo precaución, en pp. 526-532; y para el motivo especulación - tal vez el más dudo. so-, pp. 533.534 y 543-548; asi como las respectives notas.

Uno de los primeros economistas que habló de demanda de dinero por motivo de precaución fue Richard Cantillon, que en su Ensayo sobre la naturaleza del comencio en general (1755) escribe:

\begin{abstract}
Muchos propietarios, empresarios, etc., guardan siempre algun dinero contante en sus bolsas o en sus cajes para afronter casos imprevistos y no quedar exhaustos... Nunca llegamos a gastar haste el ultimo centavo; disfrutamos sabiendo que no estamos desprovistos del todo y que recibiremos un nuevo refuer. zo de ingreso antes de pagar, incluso, una deuda, con el dinero que se posees [Cantillon (1755), p. 97].
\end{abstract}

Laidler ha llamado la atención acerca de la importancia y trascendencia que tiene el reconocimiento de la demanda de dinero por el motivo precaución:

Les tenencies de dinero por motivo de precaución y la rigidez de precios provienen ambas de la miama fuente, a saber, las imperfecciones de información que caracterizan uns economia en la que la actividad eatí coordinad por el incercambio monetarion [D. Laidler (1990b), p. 10].

Bridel (1987), pp. 1.2 y 29-30, y sobre todo Bigg (1990), pp. 18-19 y 24, también afirman que en Marshall puede reconocerse el motivo especulación de demanda de dinero (aunque «tenuamentew para Bridel, ya que Marshall no llevó hasta sus ültimas consecuencias su análisis del efecto de los saldos reales y, por tanto, no logró todo el fruto que hubiese sido posible). Vid. Bridel (1987), p. 26. Gaynor (1991), pp. 38 y 40, también acepta un cierto elemento especulativo entre los motivos de demanda de dinero de Marshall, si bien se muestra cauto al respecto. Se refuerza, por tanto, la importante influencia que Marshall ejerció en la posterior elaboración de la teoria monetaria por parte de sus discipulos en Cambridge, especialmente en Pigou y J. M. Keynes, y la hipótesis de una linea de continuidad en el desarrollo de la teoria monetaria. 
bricación y venta, y puede ser modificada temporalmente por las fluctuaciones de la actividad y de la confianza comercial en general ${ }^{40}$.

Una vez más, la clave del análisis de Marshall se encuentra en los supuestos ceteris paribus que realiza ${ }^{4 !}$.

En resumen, sobre la demanda nominal de saldos en efectivo influyen el nivel general de precios (que es decir que nuestra demanda de dinero es una demanda de saldos reales); la velocidad de circulación del dinero (eso cuando Marshall hace expresa mención de esta variable, ya que no se considera en el que aquí hemos denominado kenfoque de Marshall») 42; la demanda que se realiza de metal-dinero (cuando se trata de un patrón mercancia -oro o plata-) para otros usos industriales, ornamentales o de simple reserva; el volumen de negocios o transacciones (que Marshall mide por el ingreso o renta agregada y, en otras ocasiones, por la riqueza) ${ }^{43}$; los häbitos comerciales (o en qué proporción se utilizan otros instrumentos alternativos de pago respecto del dinero, así como su invención); la distribución de la renta y del nivel social de las personas (este último elemento sólo es relevante en la demanda individual, y a nivel

40 Marshall (1923), p. 45. Estos mismos supuestos se reproducen en Marshall (1923), p. 48. Véase tambièn Marshall (1926), pp. 21-22 y 267. Marshall (1926), pp. 139-140, expone cómo otrus formas de crédito, que actúan en lugar del dinero, también afectan a la formulación de la teoria cuantitativa.

41 Es de sobra conocida la importancia de los supuestos ceteris paribus en el análisis marshalliano de la teoría de los precios, y en concreto de su teoria de la demanda. En el caso del análisis de la teoria monetaria la importancia de los ceteris paribus queda plasmada en el siguiente pasaje de Marshall:

\begin{abstract}
aAunque admitamos la doctrina de que, "permaneciendo los demés factores constentes, los precios se elevan o descienden proporcionalmente a cada incremento o disminución en el metal o metales que se utilizan como patrón de valor", considero que la cláusula condicionante, "permaneciendo los demis factores constantes", es de importancia arrolladora y exige cuidadosa atenciónw [Marshall (1926), pp. 21 y 22. Cursivas en el original].
\end{abstract}

Bridel (1987), p. 26, se equivoca cuando afirma que Marshall no especificó los ceteris paribus de la Teoria Cuantitativa. En cambio Bigg (1990), pp. 18.19 y 21, Laidler (1990a), y Gaynor (1991), pp. 38 y nota 1, y 40, señalan también la importancia de los ceteris paribus en la teoria del dinero de Marshall.

${ }^{12}$ No obstante, Marshall - como J. S. Mill - tuvo en cuenta que las variaciones en la velocidad (el lado de la demanda) eran cuando menos tan importantes como las variaciones en la cantidad de dinero (el lado de la oferta).

-... Ia condición "permaneciendo los demis factores constantes" supone que deben ser considerados por separado los cambios en el volumen de negocios (uranacciones) y los métodos de pagow [Marshall (1926), p. 22].

13 Esto crea un problema, pues ambos conceptos no son iguales. Vid. Laidler (1990a), p. 54, nota 11. Bigg (1990), p. 24, señala que Marshall utilizó en la presenteción de su enfoque de los saldos reales hasta tres posibilidades: una proporción del ingreso o renta, una proporción de la riqueza y una combinación de ambas. Véanse, respectivamente, Marshall (1923), p. 45; Marshall (1923), p. 44, y Marshall (1926), pp. 267-268, pregunta 11759. 
agregado basta con tener en cuenta la primera); el estado de desarrollo de la sociedad (término que incluye la creación y expansión de las entidades de crédito, el desarrollo del transporte y los métodos de producción o la tecnologia) 44; la población; las fluctuaciones generales del crédito, la confianza y la actividad comercial; sobre la demanda de dinero individuah las ocupaciones que las personas ejercen, sus respectivos temperamentos (aversión al riesgo, previsión de las gentes...); y, sobre la demanda de dinero agregada de una determinada moneda nacional, el «prestigio de dicha moneda 45 .

Por si se considerasen aún escasas las variables que afectan a la demanda de dinero y, por tanto, los motivos para considerar la teoría cuantitativa de Marshall como un importante refinamiento teórico, he sostenido en otra parte ${ }^{46}$ que la proporción $k$ que los individuos mantienen como saldos en efectivo depende de la tasa de interés y de las expectativas:

El dinero conservado en mano no genera ingreso alguno; por lo tanto, todos comparan (de forma más o menos automática e instintiva) los beneficios que obtendrán si aumentan su cantidad de dinero que mantienen en efectivo, con lo que obtendrian si invirtiesen algo de ese dinero en un bien - pongamos un abrigo o un piano - del que derivarán un beneficio directo, o en algún negocio industrial o un titulo bursátil, del que obtendrán un beneficio monetario ${ }^{47}$.

Conociendo la teoría de la formación del tipo de interés de Marshall no resulta atrevido interpretar que cuando el individuo se enfrenta a la decisión de mantener una proporción de sus ingresos en saldos disponibles de efectivo,

14 Estas tres últimas variables influian en la demanda de dinero indirectamente a través del desarrollo de los sustitutos de la moneda circulante (billetes, cheques, letras de cambio, pagarés...) para realizar transacciones; y eso ya había sido incluido en los ahábitos comercialean.

15 Véase Méndez Ibisate (1988a), Pp. 481.495. Obsérvese la gran importancia que Marshall concede tanto a los factores atecnológicos» o económicos como a los institucionales. Tomo eel prestigio» de la moneda como un factor atecnológicow, pues Marshall está considerando la influencia de las expectativas:

ala influencia que el crédito (reputación) de un moneda ejerce sobre el deseo de la po. bleción de conservar una parte de sus recursos directamente, en metilico o en sus bolsillos o en un banco, o indirectamente, en forme de valores o tínulos cotizables en bolea que producen una renta fija expreanda en dinero... puede ser muy importante si se deteriore. De hecho, todo aumento despropor. cionado en el volumen de moneda inconvertible tiende fícilmente a rebajar el valor de cada unidad en proporción superior a dicho aumento: porque rebajarí el crédito de la moneda e induciri a todos a conservar en forma de dinero una cantidad de sus recursos menor a la que de otra forma hubieran conservadow [Marshall (1923), pe. 47.48].

Sobre las expectatives, vid infres nota 49.

46 Véase Méndez Ibisute (1988a), pp. 495.507.

17 Marthall (1923), pp. 38-39. Un texto similar, cincuenta y dos años antes, en Marahall (1871), p. 167. 
el coste de oportunidad que debe considerar (como sugiere el texto) viene medido por el tipo de interés. Pero más aún, Marshall afirma que:

Lo que afirmo con respecto a la tasa de descuento pretende explicar, no el alza permanente en los precios, sino las mayores provisiones de moneda en los bolsillos de la gente que sostienen permanentemente los precios ${ }^{48}$.

Respecto a las expectativas como variable que influye en la demanda de dinero, baste añadir el siguiente texto de Marshall a las referencias ya hechas:

La demanda de un metal para los fines de atesoramiento se incrementa por un alza continua en su valor [una caida continua en el nivel absoluto de precios] y disminuye por un descenso continuo en su valor, porque las personas que atesoran creen que lo que ha estado subiendo de valor probablemente continuará aumentando y viceversa ${ }^{49}$.

\section{La oferta de dinero}

Como ya se ha insistido, Marshall estudió la teoria de la demanda de dinero no porque estuviese interesado en ella per se, sino porque formaba parte de la teoría del nivel general de precios ${ }^{50}$. $« \mathrm{El}$ modelo económico en el que desarrolla dicho análisis [en el «Essay on Money»] utiliza como medio de cambio

48 Marshall (1926), p. 45, pregunta 9661 . Laidler (1985) afirma que la $k$ de la ecuación de Cambridge no debe considerarse como un parimetro que permanece constante en el tiempo. Por el contrario, el tipo de interés se incorporaba como una de las variables que la afectaban, y que - por tanto- determinaban la demanda de dinero (vid. Laidler (1985), p. 50, y nota 3 en dicha pigina). Sin embargo, Laidler (1991) matiza su posición al respecto - me atreveria a decir que la cambia completamente- y trata el texto citado en la nota 47, supra, como una excepción, afirmando que Marshall no contempló -en el manuscrito de 1871 - el tipo de interés como variable que afectase a la demanda de dinero [vid. Laidler (1991), p. 62]:

49 Marshall (1926), p. 6. Vid. supra, nota 45 y los textos reproducidos en esa nota y en supra, nota 32. Respecto a las expectativas, Laidler (1991) afirma que Marshall tampoco trató la influencia de la inflación esperada sobre la demanda de dinero, reduciendo el papel que he concedido a las mismas aqui. El propio Laidler cita el siguiente texto de Marshall.

\footnotetext{
-El nivel de precios que sustentari un volumen dado de dinero, es propenso a quedar afoctado por cualquier falta de credibilidad y confianza en dicho dinero. Cuanto menor eea el crédito the confianza) de la moneda, menor seri la proporción de sus recursos que la gente desea mantener en forma de dinero.. ai el crédito de una moneda cae, su valor desciende respecto a las mercancias, incluso aunque no se produzca ningún cambio en su volumens [Marahall (1926), p. 269].

Laidler cree, no obstante, que este texto, que pareceria incluir el efecto de las expectativas de inflación sobre la demanda de dinero, aqueda bien lejos de poderse considerar como una elección marginal bien calculadaw [Laidler (1991), p. 62].

so Vid. Leidler (1990a), p. 54
} 
"las conchas de cierta clase de molusco extinguido" y produce grano» ${ }^{51}$. En este modelo simplificado Marshall afirma:

si hubiese un millón de conchas, y el ingreso de la nación fuese de sesenta millones de bushels de grano, una concha valdria, seguin la primera hipótesis [si cada individuo de la nación decide mantener un poder adquisitivo sobre los bienes en forma de dinero igual a la décima parte de su ingreso anual], seis bushels. Después del cambio en los hábitos [de modo que las tenencias de dinero cayesen a una veinteava parte del ingreso], el valor de cada concha disminuirá... hasta que cada concha valga únicamente tres bushels 52 .

He aquí un caso específico de la formación del valor del dinero segün su demanda y su oferta, que es considerada como exógena "33. Pero aunque para algunos efectos Marshall consideró la oferta monetaria como exógena, su análisis completo tomó dicha variable como endógena y, en teoría, trabajó con una oferta monetaria endógena. Más adelante, siguiendo el mismo texto anterior, Marshall generaliza su modelo a tres casos más:

Supongamos, primero, que estas conchas pueden encontrarse mediante obras de dragado, y de esta forma incrementar el número total de ellas; mantenemos el supuesto de que las conchas son la única forma de dinero y que ninguna otra cosa, a excepción de las conchas, se utiliza como dinero...

[Segundo], considerando aún que ninguna otra cosa a excepción de las conchas se utiliza como dinero, supongamos ahora que las conchas se utilizan ade. más como ornamentación y otros propósitos, siendo, de hecho, consideradas como mercancias...

Supongamos, por ültimo, que otras cosas se utilizan como dinero a la vez que las conchas: el papel o cualquier otra cosa 54 .

En el primer caso, Marshall expone que un movimiento descendente en la demanda de dinero de toda la economía podría conducir el valor de las conchas «permanentemente por debajo de su coste de producción»; pero que un movimiento ascendente podria hacer «beneficioso dragar a niveles cada vez más profundos en el aguar. En el segundo caso señala que la demanda de conchas como mercancia -independientemente de sus usos monetarios- romperia (excepto en un caso muy excepcional) la relación proporcional entre la cantidad de conchas y su valor. $Y$ en el tercer caso,

\footnotetext{
51 Laidler (1990a), p. 54.

s2 Marshall (1871), p. 168.

53 Mi opinión e interpretación del tema se exponen en Méndez Ibisate (1988a), pp. 551-556.

s4 Marshall (1871), pp. 171, 172 y 173.
} 
el efecto de estas invenciones [papel moneda y otros instrumentos] es provocar otras formas de cambio que sustituyan a aquellas en las que el dinero toma parte... [Tales invenciones] provocan que la cantidad de mercancias sobre las que las personas deciden mantener una disponibilidad de demanda en forma de dinero efectivo disminuya: [dichos instrumentos] disminuyen, asi, el valor de las conchas o (como ya podemos decir) del oro y de la plata; por lo tanto [tales instrumentos financieros en desarrollo] establecen una mayor libertad para que la mayoria de las conchas [o el oro y la plata] sean utilizadas como mercancias y, al mismo tiempo, disminuyen la mano de obra destinada a explotar las minas para obtener los medios de hacer lo que, en muchos casos, puede hacerse mejor evitando el uso del oro y de la plata 55.

Marshall sintetiza asi la teoria cuantitativa y el enfoque del coste de producción, permitiendo la integración de este último en un análisis de la oferta monetaria como variable endógena ${ }^{56}$. Marshall se percató de que el coste marginal de producción del metal precioso -que los clásicos habian considerado como el factor exógeno determinante del nivel general de precios a largo plazo- *era una variable endógena cuyo valor dependía de la naturaleza de las instituciones monetarias" ${ }^{57}$, puesto que la invención, introducción y extensión de instrumentos financieros que desempeñasen las funciones del oro y de la plata udisminuirian la cantidad de trabajo destinada a explotar las minas», quedando la mano de obra libre para ocuparse en otros sectores.

Sólo en una economia estacionaria en la que la capacidad de compra del dinero es exactamente igual al coste que rige en el margen de producción de las minas más provechosas, y en las que, por tanto, la producción sería igual a cero, podria considerarse el nivel general de precios determinado únicamente por factores técnicos 88.

Una vez más se pone de manifiesto que los elementos institucionales pesaban mucho en el análisis teórico de Marshall, también en el lado monetario de la economia 59.

"Marshall (1871), p. 173.

* * Las interacciones entre el tamaño del stock existente de metal, la proporción de dicho stock que se emplea para usos monetarios y por consiguiente su tasa presente de flujo de producción, son todas (variables) relevantes para determinar su coste de producción marginal que no es, por tanto, una variable exógenaw [Leidler (1991), p. 10].

37 Laidler (1990a), p. 55.

38 Laidler (1990a), p. 55. Texto reproducido en Laidler (1991), p. 55.

59 En Méndez Ibisate (1988a), algunas partes de los caps. IV y V, señalo la importancia que tenia para Marshall el papel desempeñado por las instituciones financieras, que creaban y desarrollaban nuevos instrumentos de cródito -a gran velocidad, según él-, debido al progreso y desarrollo experimentados en las sociedades capitalistas de su tiempo. Ello, a su vez, contribuia 
Esto no quiere decir que el coste de producción para Marshall no tuviese importancia o influencia alguna en la determinación del valor del dinero. La tenía por el lado de la oferta de dinero. Pero el coste de producción dejaba de ser, en manos de Marshall, el único determinante (o incluso el factor predominante) del valor del dinero, y ello suponia un gran paso respecto de los clásicos. Estas consideraciones sobre el coste de producción como una parte de la teoria del valor del dinero (pero no como explicación única del mismo a largo plazo) fueron matizadas pero no olvidadas por Marshall en sus escritos posteriores 60 .

\section{Qué es dinero para Marsball 61}

Hemos establecido la importancia que para Marshall tenían los instrumentos financieros y medios de pago alternativos que desempeñaban algunas funciones del dinero.

Marshall no concedió especial importancia a la distinción entre el dinero y los demás activos. Utilizó abundantemente en sus análisis una definición de dinero que consistia en monedas acuñadas de oro o plata, o moneda y billetes de banco (considerando tanto el caso en que fuesen convertibles como que no lo fuesen). Tal concepción no difiere mucho de la que hoy en día tenemos, e incluso llega a ampliar ese concepto cuando dice que «cuando no se presupone algo en contra, el término *dinerow... consiste en aquellas cosas que son por lo general (en todo tiempo y lugar) medios corrientes de pago... para adquirir bienes y servicios y sufragar las obligaciones comerciales $\$ 2$.

al progreso y desarrollo de dichas sociedades, tal como relata Marshall.

Como ha puesto de manifiesto Laidler (1991), p. 59, el contraste entre la versión de Cambrid. ge de la teoria cuantitativa y la versión de Fisher no está en una diferencia de énfasis en los factores institucionales frente a la elección individual, sino en el uso o abandono del concepto de velocidad de circulación del dinero.

60 Véanse como ejemplos Marshall (1925), pp. 200-201 [texto reproducido en Méndez Ibisate (1988a), p. 391], y Marrhall (1926), p. 269 [citado parcialmente en Méndez Ibisate (1988a), p. 576, note 73$]$.

61 Existe un tratamiento específico de este punto en Méndez Ibisate (1988a), pp. 379.383. Bridel (1987), p. 27, pone especial énfasis en admitir una definición amplia de la oferta monetaria en Marshall, en la que incluye los instrumentos de crédito como parte de la definición de dinero. Laidler (1990), segin se cita en este trabajo, y Gaynor (1991), p. 40, también serialan la inclusión del crédito como parte de la oferta monetaria, con lo cual se tranaforma dicha variable en endógena, tal como sostuve en la sección precedente.

62 Marshall (1923), p. 13. 
Pero sí consideró de crucial importancia, sin ser el primero ${ }^{63}$, el papel desempeñado por el «dinero bancario» o cuasi-dinero (los depósitos) en el sistema monetario, debido a las razones ya esgrimidas (papel de las instituciones y su desarrollo, y relevancia de la proporción en que se utilizan otros instrumentos alternativos de pago respecto del dinero como factores determinantes de la demanda y oferta del dinero y, por tanto, de su valor). Marshall expuso el analisis de lo que conocemos hoy como el multiplicador bancario de los depósitos (proceso por el que a través de los depósitos bancarios se produce una creación o expansión de la base monetaria del sistema) 64 .

Como nos revela Eshag, Marshall conocia bien el argumento de su contemporáneo Giffen, en el sentido de que la cantidad de reservas en efectivo de los báncos y, por tanto, de los depósitos bancarios, se veian afectados por el nivel de ingreso nominal ${ }^{65}$. El proceso era que un aumento del ingreso nominal, un auge, provocaría una pérdida de reservas en efectivo debido a los aumentos en la demanda nominal de saldos en efectivo. Al incluir los depósitos bancarios en la definición de dinero todo este mecanismo significaba, ahora de forma clara, que el nivel absoluto de los precios y el ingreso real afectaban a la oferta monetaria, que quedaba como una variable endógena.

\section{Otras aportaciones de Marsball a la teoría monetaria}

Es cierto que en el análisis de los economistas clásicos existieron referencias acerca de que los agentes mantenian una determinada cantidad de efectivo en sus manos para atender demandas imprevistas (es decir, una aproximación de la teoria de la demanda de dinero en términos del enfoque de Marshall). Hasta donde llega mi conocimiento, A. Smith, H. Thornton y J. S. Mill así lo hicieron; y el propio Marshall cita a William Petty ${ }^{66}$. Pero, con excepción de J. S. Mill, «tal noción no desempeñó un papel esencial en el análisis clásico ${ }^{67}$. Mill sí consideró que la demanda de saldos monetarios variaba con

${ }^{63}$ Véase al respecto las ideas presentadas por Thornton (1802) y Mill (1848).

Laidler (1990a), p. 57, cita el trabajo de J. Pennington (1829), Paper Communicated by Mr. Penninglom como uno de los primeros expositores de la expansión múltiple de los depósitos.

* Un analisis detallado, con textos de Marshall, puede encontrarse en Méndez Ibisate (1988a), pp. $452-453$ y 555.556 .

${ }^{65}$ Cf. Eshag (1965), pp. 16-18. Citado en Méndez Ibisate (1988a), pp. 555.556.

* Marshall (1923), p. 47. Y en la nota 1 de dicha pigina Marshall cita a Petty, Locke, Cantillon y Smith como autores que se preocuparon por el problema de cuánto dinero necesita una nación para llevar a cabo su comercio sin problemas. Vid supra, nota 38.

67 Laidler (1990a), p. 58. 
las fluctuaciones del ciclo económico, de forma que en un proceso especulativo alcista la demanda de saldos de efectivo disminuia, y, cuando el proceso tornaba al inverso (cuando aparecía la crisis), la pérdida de confianza asociada al mismo provocaba un aumento en la demanda de saldos en efectivo que precipitaba la caída de la economia, en ocasiones de forma estrepitosa como consecuencia de la crisis de confianza en el sistema monetario y financiero y del consiguiente pánico ${ }^{68}$.

Debido, sin duda, a su peculiar enfoque de la teoría del valor del dinero (que superaba los problemas clásicos del valor), y en particular al enfoque de la demanda de saldos reales, Marshall realizó interesantes aportaciones a la teoría del ciclo.

En un tono muy clásico Marshall comienza describiendo el ciclo como *un estado de inactividad [reposo], -luego, de mejoramiento, -crecimiento de la confianza general, -prosperidad, -alboroto, -saturación comercial, -convulsión, -tensión, -estancamiento, -agotamiento, -finalizando, de nuevo, en reposow ${ }^{69}$. Y continúa, citando y siguiendo la interpretación de J. S. Mill acerca de la ley de Say, afirmando que «lo que constituye los medios de pago para adquirir mercancías es, simplemente, mercancias», esforzándose, asi, en negar que las crisis y las fases de caida del ciclo estuviesen caracterizadas por una sobreproducción general. Sin embargo admitio, siguiendo a J. S. Mill, que saunque los hombres poseen el poder de compra, pueden decidir no utilizarlo como consecuencia de una falta de confianza ${ }^{70}$. $« E l$ resultado es un estado de desorganización comercial talw, que sólo puede remediarse «restaurando la confianza».

68 Vid. Laidler (1990a), p. 58. Vid. Méndez Ibisate (1988a), pp. 123-124. Vid., Méndez Ibisate (1988b), pp. 89-90.

69 A. Marshall and M. P. Marshall (1879), p. 153. Marshall señala que la cita es famosa y corresponde a lord Overstone. Marshall la repite en Marshall (1923), p. 246, y de nuevo cita a lord Overstone en la nota 2 a pie de dicha página.

10 A Marshall and M. P. Marshall (1879), p. 154. Este texto aparece también en Marshal] (1890), pp. 710-711.

Marshall trata también en otras obras el tema del ciclo comercial: Vid. Marshall (1887), pp. 188-211, sobre todo pp. 189-197 y vid. Marshall (1923), pp. 75.76, 247-251.

Marshall resaltó el papel desempeñado por la tasa de interés y las expectativas en el ciclo del crédito [vid. Marshall (1923), pp. 254-258, 246 y 249] y la repercusión que sobre el ciclo tienen las actuaciones de algunas instituciones financieras, como bancos comerciales e industriales, el Banco de Inglaterra, la Bolsa de Valores, o la misma situación de la organización industrial (estructure y desarrollo) [Marshall (1923), pp. 86-87, 89-90 y 258-259].

Estos ciclos crediticios - fenómenos a corto plazo- tenian para Marshall repercusiones sobre la actividad y el empleo de la economia. [Además de los textos ya citados, vid. Marshall (1913), pp. 401-402.]

Véase un estudio preliminar del tratamiento que hizo Marshall de las fluctuaciones comerciales y del crédito en Méndez lbisate (1988a), pp. 771-811. 
Hasta aqui Marshall realiza un análisis convencional clásico; pero a continuación se centra en «La conexión [existente] entre un descenso en los precios y una suspensión de la industria [(o de la actividad) que] exige un análisis más detallado» ${ }^{71}$. Y explica dicha conexión como sigue:

Rara vez ocurre... que los gastos que un fabricante debe pagar desciendan proporcionalmente tanto como el precio que obtiene por sus bienes. Ya que cuando los precios aumentan, el alza en el precio de los bienes finales [de consumo] es generalmente más rápido que el del precio de las materias primas, y siempre más rápido que el del precio del trabajo; y cuando los precios están cayendo, la caída en el precio de los bienes acabados es generalmente más rápida que la del precio de las materias primas, y siempre más rápida que la del precio del trabajo ${ }^{72}$.

«He aquí una explicación de las fluctuaciones en el ingreso real y el empleo basadas en el postulado de la rigidez de los salarios monetarios* 73 .

Además de esta ampliación de la teoría clásica del ciclo que abarcase las variables reales, cosa que ya habia hecho $H$. Thornton en 1802, Marshall tomó en consideración el comportamiento de la demanda de dinero en el curso del ciclo de forma más completa al aplicar el efecto de los saldos reales. En su artículo de 1887 «Remedios para las fluctuaciones del nivel general de precios», publicado originalmente en la Contemporary Review, después de haber realiza-

Respecto al tema de la Ley de Say en Marshall, véase Méndez Ibisate (1988a), p. 757 y el Apéndice $H$, incluido con el título aAlfred Marshall y la Ley de Saym.

11 A. Marshall and M. P. Marshall (1879), p. 155.

72 A. Marshall and M. P. Marshall (1879), p. 155.

73 Laidler (1990a), p. 59. Vid Méndez Ibisate (1988a), p. 755 (texto), y 756.

Marshall utilizó - antes que J. M. Keynes- la rigidez de los salarios monetarios a la baja como factor que impedia la restauración del equilibrio durante un proceso cíclico. $Y$ antes que Marshall, economistas cläsicos, como Thornton (1802) y Torrens, utilizaron este argumento como una causa por la que un impacto monetario afectaba el nivel de actividad real; es decir, como factor ciclico. [Vid. O'Brien (1975), Pp. 162-165, y vid. Humphrey (1991), todo el artículo, pero sobre todo pp. 4 y 7.]

En realidad, y a diferencia de algunos modelos keynesianos, J. M. Keynes no consideró la rigidez salarial como el problema fundamental por el que el modelo «clásico» no funciona.

Marshall llega a afirmar tajantemente que:

Cuando el crédito se quebranta y los precios comienzan a descender.. como los sueldos y salarios se estipulan en dinero, cuyo valor estí subiendo, el patrono pera salarios reales mis elevedos de lo que es costumbre en ese momento a menos que pueda lograr una reducción en los salarios monetarios. Es cste una tarea dificil, en parte porque los asalariados temen, y no sin razón, que una vez que hayan permitido una reducción en sus salarios nominales éstos no vuelvan a elevarse fícilmente. De modo que prefieren cesar en el trabajo antes que aceptar una reducción nominal, incluso aunque ello no supusiese una reducción real (de su salario) [Marshall (1887), pp. 191-192. Reproducido en Marshall (1923), pp. 18-19]. 
do una clara exposición de la distinción entre tipos de interés nominales o monetarios y tipos de interés reales, Marshall afirma que:

cuando los precios tienen probabilidades de subir, la gente se precipita a pedir prestado y adquirir bienes, lo que contribuye a aumentar aún más los precios... quienes trabajan a base de capital tomado a préstamo devuelven un valor real menor del que recibieron, y se enriquecen a expensas de la comunidad...

Cuando, más tarde, el crédito se quebranta y los precios comienzan a descender, todos desean deshacerse de las mercancias y adquirir dinero, cuyo valor aumenta con rapidez ${ }^{74}$.

He aqui expuesto un efecto de saldos reales, en el que las variaciones en la demanda de dinero, que responden a variaciones esperadas y observadas de variables que quedan afectadas por el transcurso del impacto cíclico (nivel de precios, tasa de inflación, tipo de interés, nivel de actividad,...), generan -a su vez- movimientos procíclicos. Esta clase de movimientos en la demanda de dinero ya había sido señalada, entre otros, por John Stuart Mill y, como he expuesto en otro lugar, fue utilizada por los miembros de la denominada Banking Scbool para propugnar la discrecionalidad relativa en las actuaciones de política monetaria por parte de las autoridades, y el manejo del dinero como instrumento de lucha anticíclica 75 .

D. Laidler expone esta misma idea de Marshall y afirma:

El mecanismo que guia lo que hoy en día denominariamos como demanda agregada fs un efecto de saldos reales, provocado por las variaciones en la cantidad demandada de dinero, que a su vez surgen de las variaciones [esperadas y] observadas de los rendimientos relativos procedentes de las tenencias de dinero efectivo y de bienes; y todo ello complementado por los efectos experimentados en el mercado de crédito por motivo de un retraso en [la adecuación de] la tasa real de interés respecto de la tasa monetaria ${ }^{76}$.

Respecto a las tasas real y monetaria de interés, Marshall hace una ulterior observación en sus Principios que remarca tanto la importancia de éstas en el ciclo, como el papel desempeñado por la tasa de interés real en la interconexión entre el lado real y el monetario de la economia:

Cuando discutamos las causas de los periodos alternos de inflación y depresión de la actividad comercial, encontraremos que se hallan intimamente conec-

74 Marshall (1925), pp. 190-191.

75 Vid Méndez Ibisate (1988b), pp. 89-90.

76 Laidler (1990a), p. 60. 
tadas con aquellas variaciones en la tasa real de interés provocadas por los cambios en el poder adquisitivo del dinero 77 .

\section{CONCLUSIONES}

He querido demostrar que, pese a sus muchas deudas intelectuales y teóricas con los economistas clásicos (o gracias a ellas), la teoria monetaria de Marshall superó inconsistencias de la teoría monetaria clásica y contribuyó a elevar dicha teoría, y a la economía monetaria, a la categoria de rama de la ciencia económica y a ser lo que hoy es.

Continuador de una línea teórica en el campo del dinero, sin embargo Marshall fue más allá que sus predecesores y elaboró, o esbozó, muchos de los avances analíticos que en teoria monetaria marcaron el desarrollo de ese campo particular de la ciencia económica en la primera mitad del siglo xx. Su peculiar enfoque microeconómico de los problemas en general le permitieron abordar el problema del valor del dinero como el de cualquier otro bien, con la ventaja de que aplicó los avances analíticos que se habian introducido (que èl habis introducido) en la microeconomia al problema particular del dinero. Ello le llevó a desarrollar -independientemente de su preocupación moral por que los individuos dispusieran de una moneda que cumpliese correctamente sus funciones- una teoria completa de la demanda de saldos reales de dinero, que incluia los distintos motivos por los que los individuos desean mantener saldos monetarios en su poder, como parte integrante de su explicación de la teoría del valor del dinero; es decir, de la teoria de ala cantidad de dinerow de los precios.

Sus incursiones en estos terrenos le llevaron también a analizar otros aspectos de la economia tales como las interconexiones entre el lado real y el monetario, y, por tanto, a tratar el problema de los ciclos y las fluctuaciones y contemplarlo como efecto de los males monetarios.

En definitiva, Alfred Marshall también aportó nuevas ideas en algunos aspectos de la macroeconomía - como ya lo habia hecho en la microeconomia-, y hasta me atrevería a afirmar que también aportó nuevos métodos con la aplicación del esquema y enfoque microeconómico a problemas macroeco. nómicos. Sus ideas y teorias fueron recogidas y desarrolladas más o menos pronto, tanto por su discipulo J. M. Keynes como por otros teóricos cuantitativos de la Escuela de Cambridge o algunos monetaristas de Chicago, como Mil-

7 Marshall (1890), Libro VI, cap. VI, secc. 7, p. 594. En general, este capitulo es una excelente muestra del tratamiento que Marahall otorga a la teoría del interés del capital. 
ton Friedman. La aplicación del esquema y enfoque microeconómicos al campo de la macroeconomía ha tenido que esperar hasta la década de los ochenta y, salvo en la «filosofia» que hay detrás, poco o nada tiene ya que ver con el desarrollo teórico de Marshall.

Pese al tiempo transcurrido y los avances teóricos alcanzados seguimos sin poder responder a la cuestión que Marshall dejó planteada en una carta, dirigida a J. M. Keynes con motivo del envío, por parte de éste al maestro, de su Tract on Monetary Reform, donde puede leerse:

Voy a morir pronto, pero si encuentro oportunidad, preguntaré a los que lleguen a las regiones celestes si han conseguido ustedes encontrar remedio contra los males de la moneda 78 .

\section{BIBLIOGRAFIA}

BeCKER, G. S., y BAUMOL, W. J. (1952): *The Classical Monetary Theory: The Outcome of the Discussion*, Economica, vol. XIX, pp. 355-376. Traducido al castellano en J. J. SPENGLER y W. R. Allen, El pensamiento económico de Aristóteles a Marshall, Madrid, Tecnos, 1971, pp. 767-785.

BigG, Robert J. (1990): Cambridge and the Monetary Theory of Praduction. The Collapse of Marshallian Macroeconomics, Londres, Macmillan Press.

BLAUG, Mark (1985): Teoría económica en retrospección Madrid, F.C.E.

BrideL, Pascal (1987): Combridge Monetary Thought. The Development of Saving-Investment Analysis from Marshall to Keynes, Londres, Macmillan Press.

Cantilion, Richard (1755): Ensayo sobre la Naturaleza del Comencio en Generah México, F.C.E., 1950.

COASE, Ronald H. (1984): aAlfred Marshall's Mother and Fathern, History of Political Economy, vol. 16, n.0 4, pp. 519-527.

- (1990): aAlfred Marshall's Family and Ancestryw, en Rita McWilliams Tullberg (ed.), Alfred Marshall in Retrospect, Aldershot, Edward Elgar Publish., pp. 9-27. Una versión preliminar de este articulo fue leída en el trascurso del Seminario «Alfred Marshall's Principles of Economics - 100 Years* celebrado en la Universidad de Cambridge (Faculty of Economics and Politics), del 28 al 30 de agosto de 1990.

EshaG, Eprime (1965): From Marshall to Keynes. An Essay on the Mometary Theory of the Cambridge Scbool, New York, Augustus M. Kelley.

Friedman, Milton (1949): «The Marshallian Demand Curvew, The Joumal of Political Economy, vol. LVII, pp. 463.495. Existe traducción castellana en M. Friedman, Ensayos sobre economia positiva, Madrid, Gredos, 1967, pp. 47-95.

GaYNor, W. B. (1991): «Price Trends and Economic Crises in Marshall's Monetary Theorym, Jourmal of the History of Economic Thought, vol. 13, n. ${ }^{\circ}$ 1, pp. 37-53.

78 Marshall (1925), p. 33, nota 2. 
Hicks, J. R. (1975): Ensayos críticos sobre teoría mometaria (2." ed.), Barcelona, Ariel.

HUMPHREY, Thomas M. (1991): «Nonneutrality of Money in Classical Monetary Thought, Economic Review. The Federal Reserve Bank of Ricbmond, vol. 77, n. 2 , (marzo-abril), pp. 3-15.

KEyNES, John Maynard (1925): «Alfred Marshall. 1842-1924», en A. C. Pigou (ed.), Memorials of Alfred Marshall, New York, Augustus M. Kelley, 1966, pp. 1-65. Existe una mala e incompleta traducción española en Alfred Marshall, Obras Escogidas, México, F.C.E., 1949, pp. IX.LXXXII.

- (1936): The General Theory of Employment, Interest and Money, Londres, Macmillan \& Cambridge University Press, 1973. Existe una mala traducción española en México, F.C.E., 1965 (2." ed. corregida).

KRISHNASWAMY, A. (1941): «Marshall's Theory of Money and Interest», Tbe Indian Journal of Economics, vol. 22 (octubre), pp. 121-143. Reproducido en John Cunningham Wood (ed.), Alfred Marshall. Critical Assessments, vol. III, Londres, Croom Helm, 1982, pp. 136-153.

LaIDleR, David E. W. (1985): The Demand for Money. Theories, Evidence, and Problems, (3." ed.), New York, Harper \& Row.

- (1990a): «Alfred Marshall and the Development of Monetary Economics*, en John K. WhITAKER (ed.), Centenary Essays on Alfred Marshall Cambridge, Cambridge University Press, pp. 44-78.

(1990b): Taking Money Seriously and Other Essays, Cambridge (Massachusetts), The MIT Press.

- (1991): The Golden Age of the Quantity Theory, Londres, Philip Allan.

Marshall, Alfred (1871): *Essay on Money* y *A Mathematical Note on the Value of Money», en J. K. WhItakeR (ed.) The Early Economic Writings of Alfred Marsball. 1867-1890, (2 vols.), Londres, Macmillan and Co., 1975, vol. 1, pp. 164-177.

- (1887): «Remedies for Fluctuations of General Prices», en A. C. PIGou (ed.), Memorials of Alfred Marsball, New York, Augustus M. Kelley, 1965, pp. 188-211. Existe traducción española en Alfred Marshall, Obras Escogidas, México, F.C.E., 1949, pp. 35-59.

- (1890): Principles of Economics (9." ed., Variorum), C. W. Gulllebaud (ed.), London, Macmillan and Co., 1961, vol. I. Existe traducción española de la 8.' edición inglesa (1920) de Emilio Figueroa, con prólogo de Manuel de Torres, en Madrid, Aguilar, 1948 y 1963.

- (1913): Elements of Economics of Industry (4." ed.), vol. I, Londres, Macmillan, 1939 (reimpresión).

- (1923): Money, Credit and Commerce, New York, Augustus M. Kelley, 1965.

- (1925): Memorials of Alfred Marsball, A. C. Pigou (ed.), New York, Augustus M. Kelley, 1965.

- (1926): Official Papers by Alfred Marshall, J. M. KeYnes (ed.), Westport (Connecticut), Greenwood Press, 1979.

- and Marshall, Mary Paley (1879): The Economics of Industry, Londres, Macmillan.

MENDEZ IBISATE, Fernando (1988a): La teoria monetaria en Alfred Marshall, Madrid, Editorial de la Universidad Complutense. Tesis Doctoral.

- (1988b): *Teorias decimonónicas del dinero en el siglo $\mathrm{xx}$, Información Comercial Española, n. 656 , pp. 79-92. 
MnL, John Stuart (1848): Principles of Political Economy, J. M. Robson (ed.), Collected Wotks of John Stuart Mill, vols. II y III, Londres, University of Toronto Press \& Routledge and Kegan Paul, 1968. Traducido al castellano en México, F.C.E., 1978.

O'Brien, D. P. (1975): The Classical Economists, Oxford, Clarendon Press. Existe una excelente traducción española de Carlos Rodriguez Braun en Madrid, Alianza Ed., 1989.

PatinxIn, D. (1963): Dinero interes y precios, Madrid, Aguilar.

Rist, Charles (1966): History of Monetary and Credit Theory. From Jobn Law to the Present Day, New York, Augustus M. Kelley. Primera edición ingless en 1940.

Thornton, Henry (1802): An Enquiny into the Nature and Causes of the Paper Credit of Great Britain F. A. HaYEK (ed.), Londres, Frank Cass and Co, 1962.

WhITAKER, John K. (1972): *Alfred Marshall: The Years 1877 to 1885w, History of Political Economy, vol. 4, núm. 1, pp. 1-61.

(ed.) (1975): The Early Economic Writings of Alfred Marsball. 1867-1890 (2 vols.), Londres, Macmillan and $\mathrm{Co}$. 